\title{
Patrimonio rural de Vila-real: los molinos
}

\author{
María del Pilar Gozalbo Herrero
}

\section{Introducción}

La vida de Vila-real, como la de tantos asentamientos humanos, ha estado vinculada desde sus orígenes a la presencia del agua. Dos hechos históricos determinan el surgimiento de la población y la extensión de sus terrenos de cultivo en este lugar de la Plana:

- La concesión de una acequia nueva, la séquia Major, hecha por el rey Jaime I de Aragón.

- La justa sentencia de distribución de las aguas del río Mijares emitida por el conde de Ribagorza en 1347.

Pero el agua de la séquia Major y de la red de canalizaciones que de ella provienen no solo sirvió para el regadío. Aprovechó también para suministrar los pozos del interior de la villa, los aljibes de alquerías y viviendas rurales, para los abrevaderos del ganado y limpieza doméstica y también fue la fuerza motriz necesaria para los molinos harineros y para algunas de las antiguas industrias.

La primera vez que se menciona la séquia Major de Vila-real es en 1272 cuando, al citar los límites de algunas tierras que se conceden durante aquel año, se habla de la acequia nueva que el rey mandó construir. Lógicamente, su edificación tuvo que iniciarse con anterioridad a dicha fecha y no acabó hasta 1282, pues se hizo en fases sucesivas.

\section{Clasificación de los molinos}

Existen diferentes clasificaciones de los molinos dependiendo del autor:

Glik, en 1970, plantea la división de los molinos en función de la forma de impulsar las ruedas para hacer funcionar el mecanismo. Así pues, los hay de impulsión alta y de impulsión baja.

Roselló (1993: 46) considera que la nomenclatura que se utiliza para los diversos artefactos en nuestras tierras, hasta el momento, no es clara.

Barceló distingue entre molinos de rueda de plano horizontal y eje vertical, que se conocen como andalucins, y los de rueda vertical o molins senyorials. Barceló también insiste sobre la naturaleza feudal de los molinos de la Cataluña medieval y establece una diferencia entre la organización feudal del espacio agrario y las estructuras agrarias de al-Ándalus, no feudales.

Selma (1993: 55), en esta misma línea de investigación, distingue los molinos originalmente no feudales construidos por los musulmanes, apropiados en la conquista por los cristianos, y los molinos edificados por los cristianos de acuerdo con las normas propiamente feudales.

Glik (1993: 55) responde que no hay un único modelo de molino feudal. En estas tierras, la mayor parte de los molinos eran propiedad de señores 
que los arrendaban por un cens; los arrendatarios explotaban los molinos como establecimientos comerciales y no tenían por qué identificarse con el molinero.

Aparici (1996: 72), en el Manual del Consell (1464, 1465), deja constancia del arrendamiento del molí del Cap de Terme y del molí d'en Falcó cuando éste pasa a ser propiedad de la villa entre 15081510. Aparici distingue también entre los molinos hidráulicos y los molins de sang, impulsados por fuerza animal.

No obstante, a pesar de la dedicación de tantos estudiosos sobre ese tema, no se llega a una clasificación precisa y clara que les resulte convincente para lograr un consenso.

En este trabajo, se proponen dos clasificaciones:

- Por orden cronológico: agrupándolos por edades, por siglos y con el año en que haya constancia documentada.

- Por su ubicación en el territorio: en el río Mijares, en la séquia Major y sus dos ramales, Sobirana y Jussana.

\section{Diseño arquitectónico}

Estas construcciones se basan en unas estructuras de muros de carga, generalmente paralelos a la fachada, con un eje transversal. Sobre el tipo básico de construcción pueden aparecer variaciones notables.

La cubierta se soluciona tanto a una como a dos aguas y, a veces, llega a conformar una fachada rectangular apaisada. La planta inferior dispone de un espacio deambulatorio o de recepción junto con las diferentes dependencias del molino con las moles para moler. La parte alta está ocupada por las habitaciones de los propietarios o arrendatarios, presentando a veces una rica decoración parietal: geométrica, figurativa o floral. Los techos, artesonados en madera, y, en los suelos, se introducen las rajoles como pavimento. También hay uno o más hogares o llars de foc. El segundo piso se destina a almacén de grano. Los corrales mantienen las formas usuales.

La parte de la vivienda doméstica del molino puede estar situada también en la planta baja, gene- ralmente en el espacio del fuego con el hogar y la cocina; las habitaciones de los dormitorios ocupan casi siempre el primer piso.

\section{Importancia}

Dos productos imprescindibles en la dieta del hombre medieval eran la harina y el aceite; ambos se obtenían mediante la molienda del trigo y la aceituna, respectivamente, en los molinos. Por esa razón, no es de extrañar que todo lo relacionado con la molinería esté perfectamente tipificado en las ordenanzas que se establecieron para evitar el menor fraude.

El molino resultaba una infraestructura cara, por lo cual, el propietario solía ser alguien adinerado que lo tenía como negocio y dejaba su funcionamiento en manos del molinero con distintas condiciones pactadas. A menudo, eran varios los propietarios de un mismo molino.

En Vila-real, los molinos se ubicaban escampados por el término; los hidráulicos, junto a su fuente de agua correspondiente, y los de tracción animal, escampados por cualquier lugar, incluso en la propia villa. Según supone José M. ${ }^{\text {a }}$ Doñate (1990: 99123), la existencias de molinos en la villa se debió al hecho de asegurar la molida en unos momentos que la población estaba siendo asediada por las tropas de Fernando de Antequera.

\section{Cantidad}

La molinería en Vila-real ha sido un tema muy estudiado por diversos autores sin que, a pesar de la abundante documentación conservada, hayan llegado a conclusiones definitivas sobre el número de molinos que han existido en sus tierras durante los últimos siete siglos. A esta variación de resultados contribuyen diversas cuestiones:

- Los frecuentes cambios de propietarios en un mismo molino, con el consiguiente cambio de nombre.

- La coincidencia o alternancia de los propietarios en molinos de características diversas.

- El nivel de profundidad del estudio y de las fuentes de información. 
Investigando en diferentes fuentes, la variación de número resulta notoria: desde diez o doce molinos hasta diecinueve e incluso más de treinta, cifra esta última que se documenta en la obra del Dr. Jacinto Heredia, Els noms de lloc al terme de Vila-real.

La primera donación sobre molinos fue hecha por Jaime I a Pere Garcés el 26 de febrero de 1274 respecto a la reconstrucción de un molino en estado ruinoso preexistente a la fundación de la vila.

La primera creación efectiva de molinos corresponde a los judíos Ramón Iuiac e Issac de Castelló en el año 1279. En este año, D. Pedro III, accediendo a sus instancias, les concedió licencia y autorización para que pudieran construir dos molinos harineros en el término de Vila-real y que pudieran utilizar para ello el agua de la acequia de esta villa. No queda constancia de que llevaran a efecto dichas construcciones.

El primer padró de riquesa conservado (siglo xIV) evidencia ya en completo funcionamiento los molinos d'en Bertran, d'en Folch, d'en Gamisa, de na Marqua y los molinos Nou, d'en Pegueroles y d'en Torner, los tres con sus respectivas variantes de nombre. Y el conocido como de la vila, que es, posiblemente, el más antiguo y de más larga trayectoria. Todos ellos están datados en 1360.

Dos años después, en 1362, se pueden encontrar documentados en la claveria de Joan Çavila los molinos d'en Giner y d'en Soler.

En 1379, claveria de Marco de Calaceyt se nombra el molí d'en Valls. Y, en 1387, la claveria de Ferrer Colomer, el de Na Blanqua.

A comienzos del siglo siguiente (siglo $\mathrm{xv}$ ), se reconocen dos molinos en extremos opuestos del término. Por el de Cap de Terme, que consta en 1406, Manual de Consells. Este molino fue concedido a Jordá de Calasseit en 1324, pero se edificó con posterioridad y tuvo una actividad escasa hasta su cierre en 1464 en que lo asumió el Consell de la Vila, que lo alquila a beneficio del erario público hasta la desamortización de 1835 . El otro molino se concedió a Miquel Forés. Se ubica en el río Mijares tocando al término de Onda. Unos años más tarde, pasará a la familia d'en Llop, procedente de
Betxí, que dejará su nombre al molino y al camino que lleva a él desde la población vecina.

También corresponden a este siglo los molinos de Font, 1433, Protocols notarials de Guillem Oçello; el d'en Oçello, 1433, Manual de Consells; el del Batell, 1455, claveria de Bernat Juneda y el del Falcó, 1465, Batllia, Establiment del molí d’en Falcó.

Ya en la Edad Moderna, siglo XVI, se documentan los llamados d'en Pauner y d'en Salvo en 1527-1529, en Padró de Peita. Y el del Frontó, 1555. Llibre de Peita.

Al siglo XVII corresponden los molinos de $\mathrm{Na} \mathrm{Vi-}$ dala en 1603-1604, Manual de Consells; el d'en Miquel Franch en 1604, Manual de Consells; el d'en Roselló en 1611, Padró de Riquesa, y el molí dels Frares en 1668, Judiciari. Y comienzan a proliferar al levante de la sèquia Major y en los alrededores del camí vell de Burriana, diversos trulls o molinos de fuerza animal, que permitirán identificar a la partida como la dels Tres Molins.

En el s. XVIII, la nueva dinastía borbónica establece unas modificaciones legislativas que incluyen como estímulo económico la concesión de diversas explotaciones molineras adjudicadas a Juan Ortells, a Vicent Cantavella, a Francisco Paloma y a Manuel Bisbal. De este siglo se documentan el molí de Palos en 1730, Padró de Riquesa; el del Colomer en 1770, Padró de Riquesa, y el de Cantavella con fecha de funcionamiento 26 de septiembre de 1774, por concesión del Batlle General.

En la Edad Contemporánea, en el s. XIX, constan en documento estos molinos: molí de l'Ermita o de Pedro Benedito en 1813, Padró de Riquesa; el d'Ortells en 1813, Padró de Riquesa; el molí de Barba en 1843, en el Padró de Riquesa, molino en activo en la actualidad con el nombre popular de moli $\mathrm{Pa}$ quero. También hay constancia del molí de Bisbal en 1858, Llibre d'Actes; este antiguo molino harinero se destinó posteriormente a la producción de hielo y de borra y, en sus últimos años, a la fabricación de tatxes o puntas de París hasta su destrucción en la riada de 1952. El molí de Paper en 1860, creado probablemente sobre un antiguo molino, como motor de una fábrica de papel, también proporcionará energía eléctrica aprovechando la fuerza hidráulica durante la noche; se le conoce como Llum 


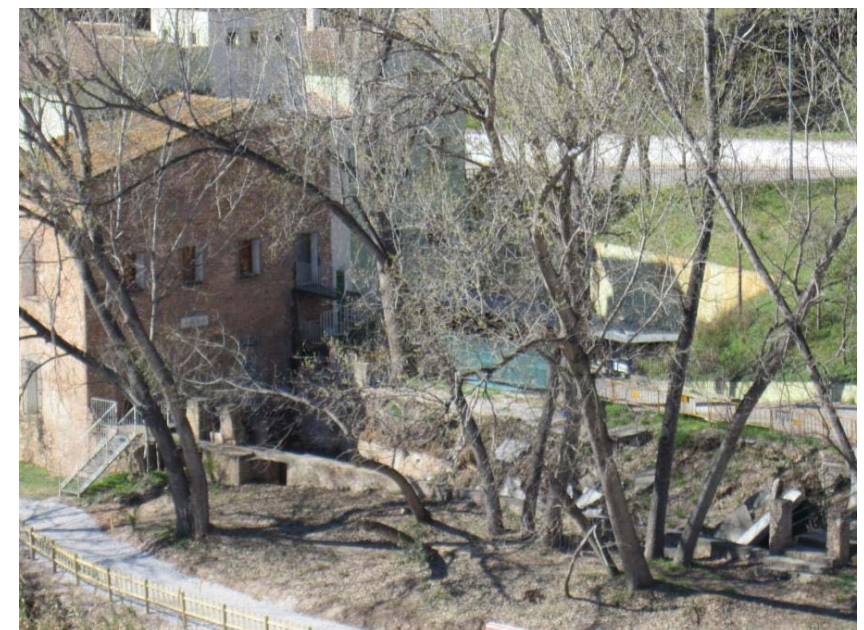

Figura 1. Molino de L’Ermita

de Tol, apodo de su propietario. Y, por último, el molino de Uvite en 1865, en el Llibre d'Actes.

Ya en el siglo xx, el molino de Serrano es nombrado por Benito Traver en su libro Historia de Villarreal (1909); debió estar muy poco tiempo en funcionamiento y fue destruido por la gran riada de 1922.

\section{Relación de molinos}

En la siguiente relación o lista de molinos consta el año en que se le nombra por cualquier referencia sobre él mismo o porque se toma como referencia de lugar o es parte de conflicto $u$ otra circunstancia. No se trata de la fecha de su construcción o puesta en funcionamiento, sino de cuándo se nombra explícitamente.

Las anotaciones aparecen en distintas fuentes documentales:

- Padrons de Riquesa: lista de los ciudadanos y de sus haciendas.

- Llibres d'Actes: actas de las sesiones del Ayuntamiento.

- Llibres de les Claveries: registros contables del funcionario municipal que tenía la responsabilidad de los pagos en el Ayuntamiento.

- Manual de Consells: libro donde quedaba escrito lo tratado en el Consell.

- Libres d'Ordinacions: disposiciones u ordenanzas municipales en las distintas materias municipales.

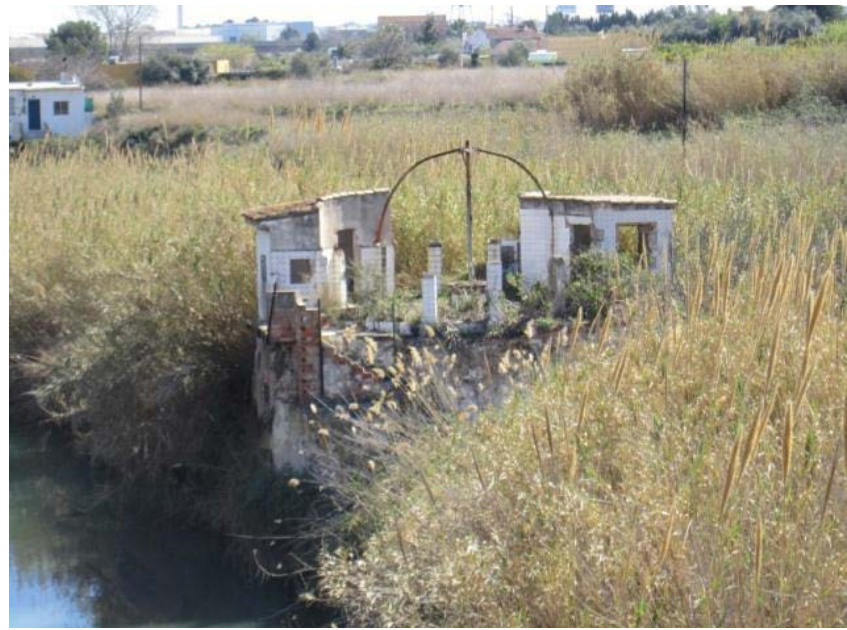

Figura 2. Molino de El Terraet. Río Mijares

- Cartes del Batlle General: edictos o disposiciones del Batlle o alcalde general.

- Protocols notarials: todo tipo de asuntos ante notario, en este caso, sobre molinos.

- Llibres de Peita: registro de los pagos del impuesto directo ordinario.

- Judiciaris: libros de actuaciones judiciales o conflictos entre partes.

- Arxiu de la Comunitat de Regants: libro de anotación de las incidencias sobre el uso del agua tanto para riegos como su uso en los molinos.

En la segunda relación, como se puede apreciar, se tiene en cuenta el emplazamiento respecto a la fuente de alimentación del agua, ya sea directamente del río Mijares o de las acequias Major, Sobirana y Jussana.

La diferencia del número de molinos en un lugar u otro no es significativa, aunque la construcción junto al río o en su propio cauce siempre ha supuesto un grave riesgo para su integridad; estos molinos han sufrido el impacto de las periódicas riadas a lo largo de los siglos y su presencia ha fluctuado en función de si eran o no reconstruidos.

Desde antiguo, ha habido molinos aceiteros dispersos por el término movidos por fuerza animal, o eléctrica los más recientes, verdaderas industrias molineras. 


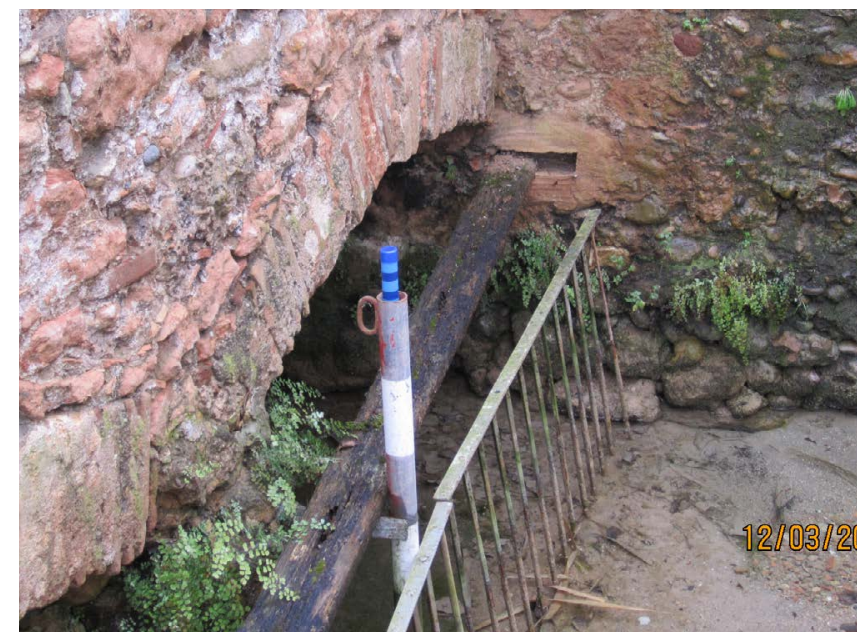

Figura 3. Detalle de un medidor de agua

\section{Clasificados por antiguedad}

\section{Edad Media}

Siglo XIII

- Garcés, d’en Pere (1274)

- Iuiach, de Ramón (1279)

- Issac, de (1279)

Siglo XIV

- Bertrán, d’en (1360)

- Folch, d'en (1360)

- Gamisa, de (1360)

- Marcha, de na (1360)

- Nou (1360). Variantes de nombre: Nou de la vila, molí (1552); Consell, del (1586)

- Pegueroles, d'en (1360). Variante de nombre: Roqueta, de la (1525)

- Torner, d'en (1360). Variantes de nombre: Reus, mossèn (1360); Peguea, de la (1360); Ayç, Arnau (1397 1398); Millars, riu de (1502); Terraet, del (1865)

- Vila, de la (1360)

- Giner, de Miquel (1362)

- Soler, de Miquel (1362)

- Valls, d'en (1379)

- Blanca, na (1387)

Siglo XV

- Cap de Terme (1406). Variante de nombre: Calasseit, de (1412)
- Çabater (1425)

- Pont, del (1430). Variantes de nombre: Frontó, del (1525); Molinet, el (1848); Vell (a partir de la riada de 1922)

- Forés, de Miquel (1432)

- Font, de (1433)

- Ocelló, d’en (1433)

- Batell, del (1455)

- Falcó, d’en (1465).Variante de nombre: Inglés, d' (1595)

\section{Edad Moderna}

\section{Siglo XVI}

- Pauner, d'en Joan (1527-1529)

- Salvo, d'en (1527-1529)

- Frontó, del (1555)

Siglo XVII

- Vidala, na (1603-1604)

- Franch, de Miquel (1604)

- Roselló, en (1611)

- Frares, dels (1668)

Siglo XVIII

- Palos, de (1730)

- Colomer, del (1770)

- Cantavella, de (fecha de funcionamiento: 26/09/1774). Variantes de nombre: Barcarrota (1863)

- Evaristo (1864)

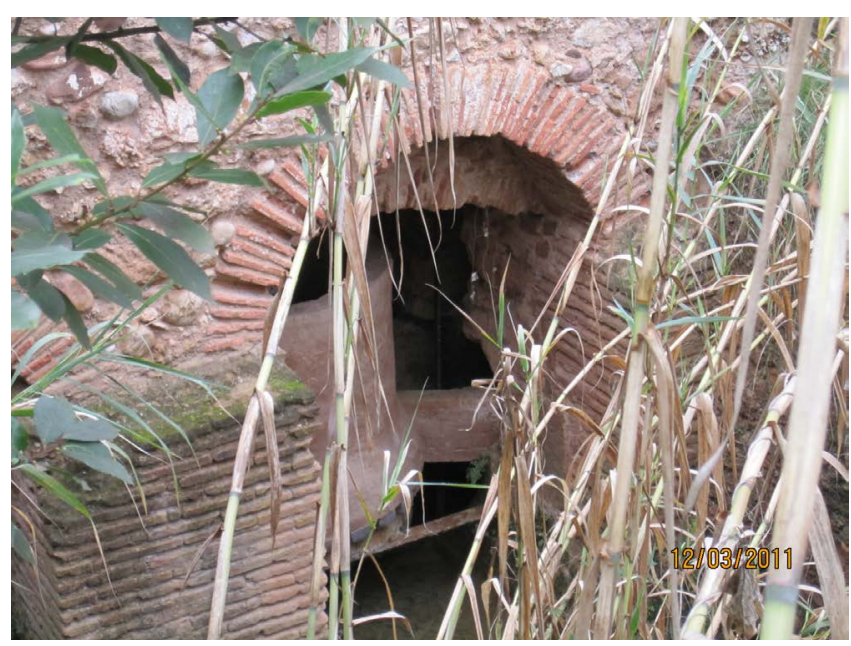

Figura 4. Detalle de un entrador de agua 


\section{Edad Contemporánea}

Siglo XIX

- Ermita, de l'/ Benedito, de Pedro (1813)

- Ortells, d' (1813); Variantes de nombre: de Prades (1841); d’Alma (1853)

- Barba, de (1843); Variantes de nombre: de Simeón (no consta fecha); de Paquero (1901)

- Bisbal, de (1859); Variantes de nombre: de Sanmillán (1877); de Tatxes (destruido en la riada de 1952)

- Paper, molí de (1860); Variantes de nombre: Molí industrial de paper y Llum de Tol (1895 1897)

- Uvite, de (1865)

Siglo xx

- Serrano, de (1909)

\subsection{Clasificados por ubicación}

\section{Río Mijares}

\section{Partida Madrigal}

- Barba, de. Otros nombres: de Simeón y de Paquero

- Batell, d'en

- Bisbal, de

- Çabater

- Ermita, de l' o de Benedito

- Frontó, del

- Ocelló, d'en

- Paper, de. Otros nombres: Fábrica papelera, Llum de Tol

- Torner, d’en. Otros nombres: de mossén Reus, de la Peguea, d'Ayç, del riu Millars, del Terraet y de Jota.

Partida Les Solades

- Franch, de

- Pont, del. Otros nombres: del Frontó, el Molinet y Vell

- Un molí (nombre y cronología sin determinar)

Partida sin determinar

- Uvite, de Vidala, na

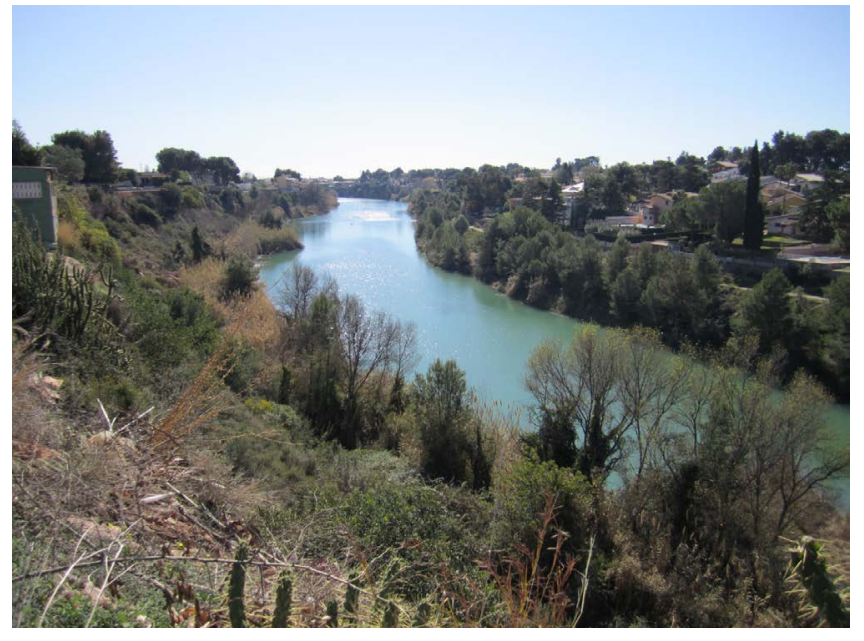

Figura 5. Río Mijares

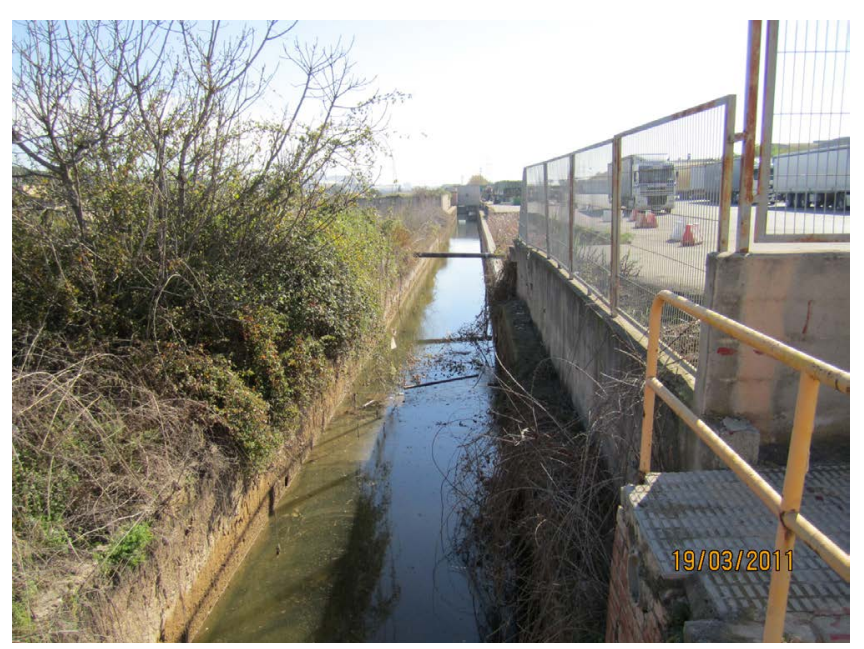

Figura 6. Séquia Major

\section{Séquia Major}

Partida Madrigal

- Giner, de Miquel

- Rosselló, en

- Soler, de Miquel

Partida Les Solades

- Nou. Otros nombres: del consell y de Santa Sofía; d’Ortells; de Serrano

Partida Carinyena

- Els Tres Molins, molí

Partida de Carinyena (Major Sobirana)

- Cantavella, de. Otros nombres: de Barcarrota y d'Evaristo

Partida Cap de Terme (Major Jussana)

- Blanqua, de na 
- Cap de Terme. Otro nombre: de Calasseit

- Falcó, d’en. Otro nombre: d'Inglés

- Font, de

Partida Carinyena (Major Jussana)

- Frares, dels

- Palos, de

- Pegueroles, d'en. Otro nombre: de la Roqueta

- Salvo, d'en

- Valls, d'en

- Vila, de la

Partida Les Solades (Major Jussana)

- Folch, d'en

\section{Sin referencias de localización}

- Bertrán, d’en

- Gamisa, de

- Joan Pauner, d'en

- Marqua, de na

\subsection{Sin referencias de su construcción}

- Garcés, Pere, donación en 1274 por Jaime I, sobre las ruinas de otro molino

- Iuiac, Ramón, licencia en 1279 por D. Pedro III, en la acequia de la villa.

- Issac, licencia en 1279 por D. Pedro III, en la acequia de la villa.

\section{Detalles del Molino Paquero}

\section{Ficha técnica}

Descripción: molino en el río Mijares, en la partida del Madrigal.

Localización: 3957’40”

Variantes: Molí de Barba, molí de Simeón.

Documentación: 1901, Llibre d'Actes, fol. 86 (AMV 4002): «proyecto de establecer una fábrica de papel en el río Mijares en el mismo edificio denominado molino del Paquero».

Comentario: concedida su construcción en 1776 a favor de Francisco Paloma y Vicente Bellmunt, después de tener diversos propietarios, en 1907 fue adquirido por la familia Montoliu que continua haciéndolo funcionar en la actualidad.

\section{Datos históricos}

Es uno de los nuevos molinos autorizados en Vila-real por el intendente general del reino de Valencia en los años 1774-1776. Este fue establecido concretamente el 6 de septiembre de 1776 a favor de Francisco Paloma y Vicente Bellmunt, vecinos de Valencia, con un censo a la hacienda real de 20 sueldos. Según el texto, estaba situado en el río, en la partida del Molló de Borriol, limitando aguas abajo con el azud y por la parte de arriba con el Bassello.

Desde 1901 consta su nominación como Paquero, pero el primer nombre que tiene constancia escrita es el de Barba, en 1843, Padró de Riquesa, fol. 325 (AVM 889: Partidas tierra secano, n. ${ }^{\circ}$ 1): «al garroferal de Bayer donde el camino de Castellón a Onda toca en el río o bien sea el rincón de la parte de arriba del molino titulado de Barba».

A mediados del siglo XIX era propiedad de los herederos de José Molina Costa, con una producción media-alta respecto al resto de molinos del término de Vila-real. En 1854 tuvo un pleito con el molino d'en Llop, situado inmediatamente aguas arriba, porque su azud en el río rebalsaba demasiada agua y el efecto de regolfo afectaba la salida de los cárcavos del molino superior.

En 1911, C. Sarthou lo cita como molino de Simeón. No obstante, la historia oral recoge la venta por parte de Luis Lavalle, propietario de la concesión de un salto de agua de 2 metros con un caudal de 600 l/s desde el año 1907, a José Montoliu en el mismo año.

A mediados del siglo xx ya lo explotaba Salvador Montoliu, padre del actual molinero Manuel, con una producción que superaba los $9400 \mathrm{Qm}$. Actualmente, este es el único molino de Vila-real que tiene reconocidos sus derechos de aguas sobre el río Mijares por sentencia del Tribunal Superior de Justicia de la Comunidad Valenciana en 1994, en resolución al contencioso administrativo presentado por los actuales propietarios contra la Confederación Hidrográfica del Júcar, que anuló sus derechos de aguas sobre el río. La sentencia le reconoce 


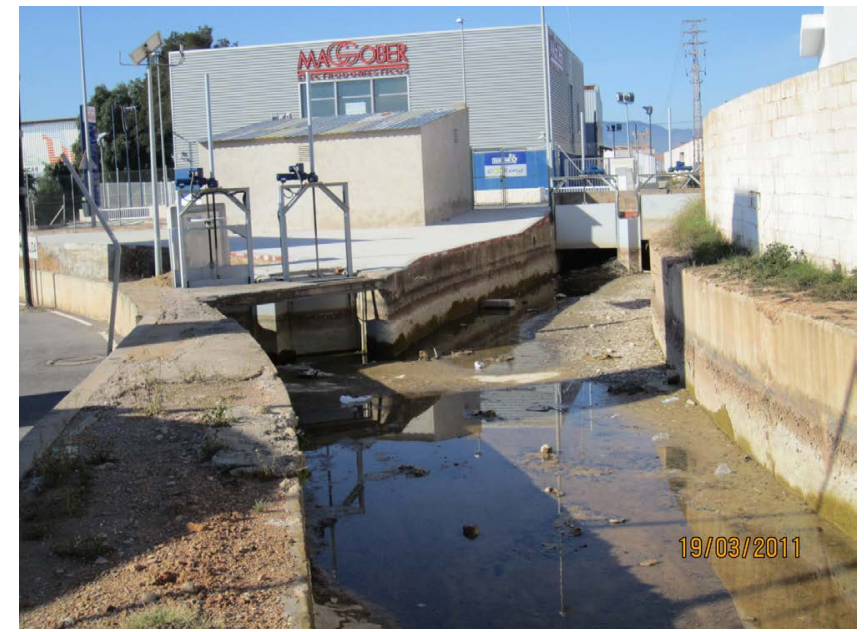

Figura 7. Bifurcación de la séquia Major en dos acequias: Sobirana y Jussana

los derechos adquiridos en 1907, destinándolo solo a la molienda.

\section{Descripción}

El casal primitivo estaba formado por una pequeña sala situada sobre la acequia o canal de abastecimiento que funcionaba como sala de muelas. Una construcción mayor sobre la ladera servía de almacén y vivienda del molinero y su familia. El conjunto se ha ido completando con el paso del tiempo, añadiendo otras dependencias y corrales en torno a la primitiva construcción.

El lugar se utiliza todavía como residencia del molinero, que ha realizando las obras necesarias de reparación y conservación de maquinaria y mejoras en su estructura. La sala de muelas fue la más afectada al levantarse una planta superior, probablemente para ubicar en ella maquinaria moderna de limpias y cernedoras.

El edificio original es una obra de mampostería vista, que utiliza el ladrillo en las bóvedas de los cárcavos y en los diversos vanos y ventanas.

Las instalaciones del molino, como se supone, están en un estado de conservación muy bueno, que permite su funcionamiento. Se conserva la maquinaria completa de dos muelas, una catalana para moler cereales y otra francesa. No se conserva la limpia ni la cernedora, que separaba la harina según sus diferentes calidades.

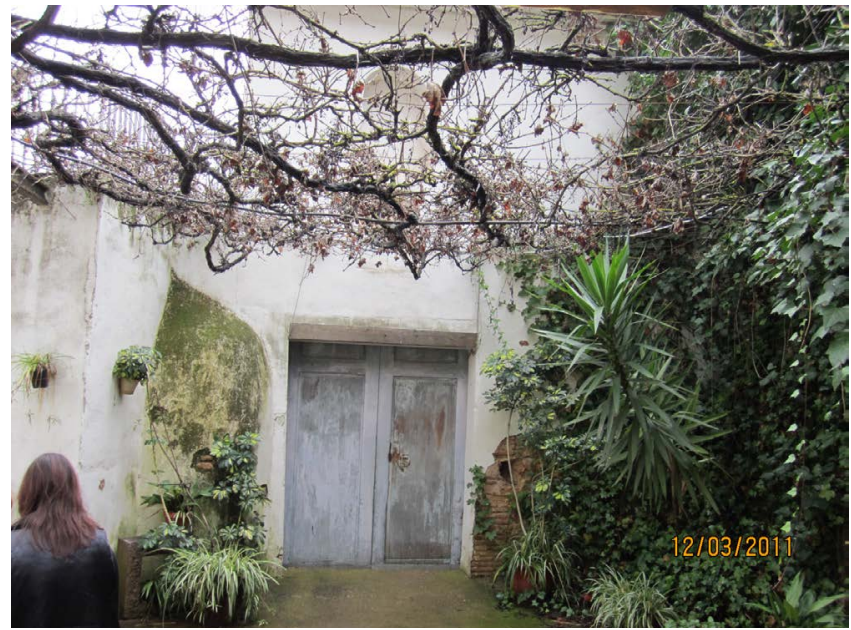

Figura 8. Molino Paquero, fachada principal

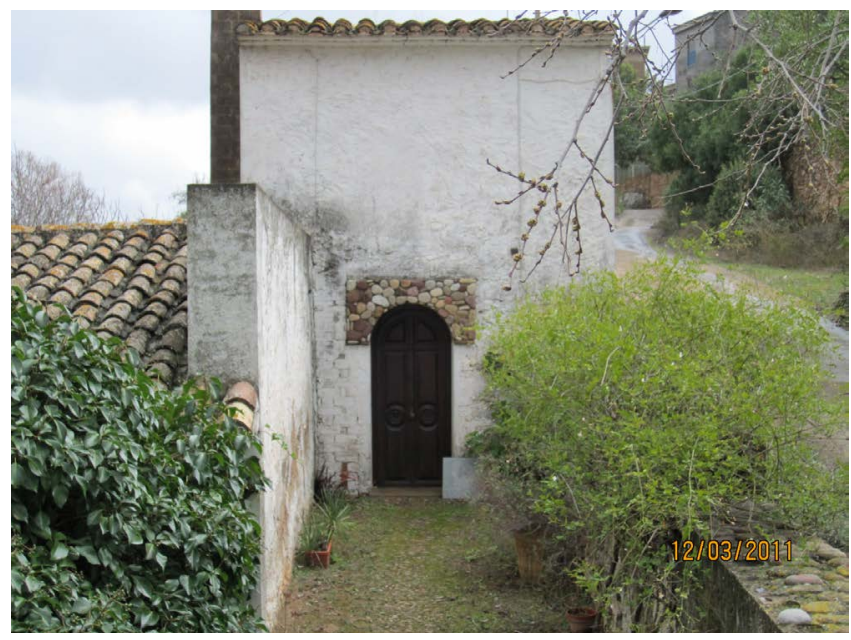

Figura 9. Molino Paquero, fachada trasera

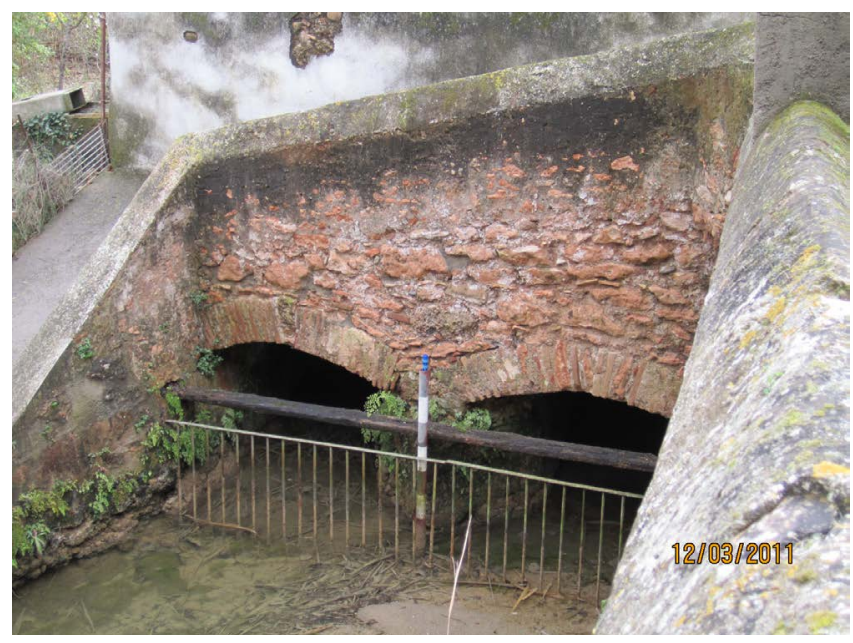

Figura 10. Frontal del medidor de agua 


\section{Sala de maquinarias}

La parte hidráulica que genera la fuerza motriz presenta unas características peculiares y novedosas. Dentro de los dos cárcavos donde se encuentran los rodetes que, impulsados por el chorro de agua, accionan el mecanismo del molino, se instalaron sendos regolfos con el objeto de aumentar su capacidad motora. De esta experiencia solo existe otro ejemplo en la Molineta de Almazora y se lleva a cabo cuando los caudales son reducidos.

En el estudio de este molino caben destacar las aportaciones del molinero y propietario, Manuel Montoliu, que ha mostrado sus dependencias y la maquinaria en perfecto estado de uso y ha compartido sus explicaciones y detalles de su historia más actual, dando todas las facilidades para realizar un reportaje fotográfico, del que se adjunta una muestra.

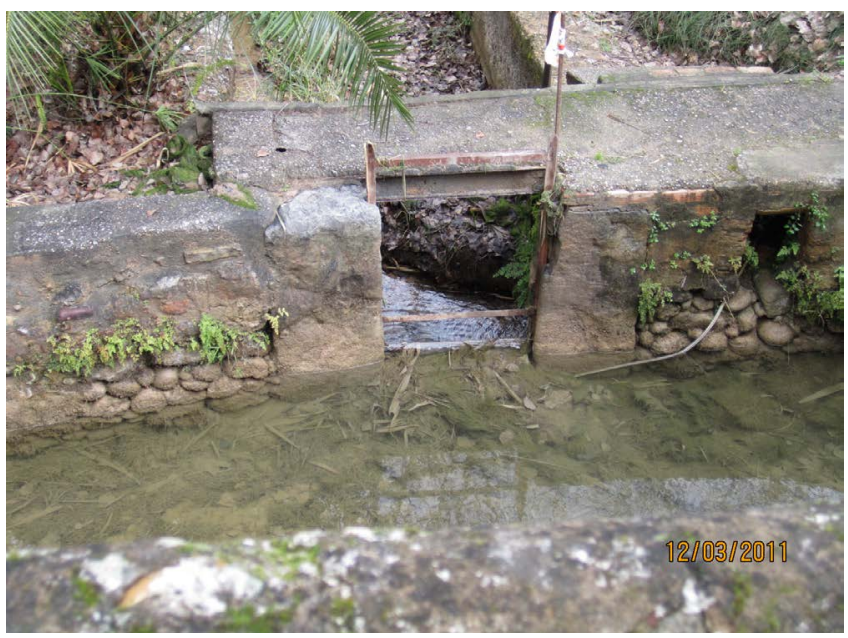

Figura 11. Entrador de agua

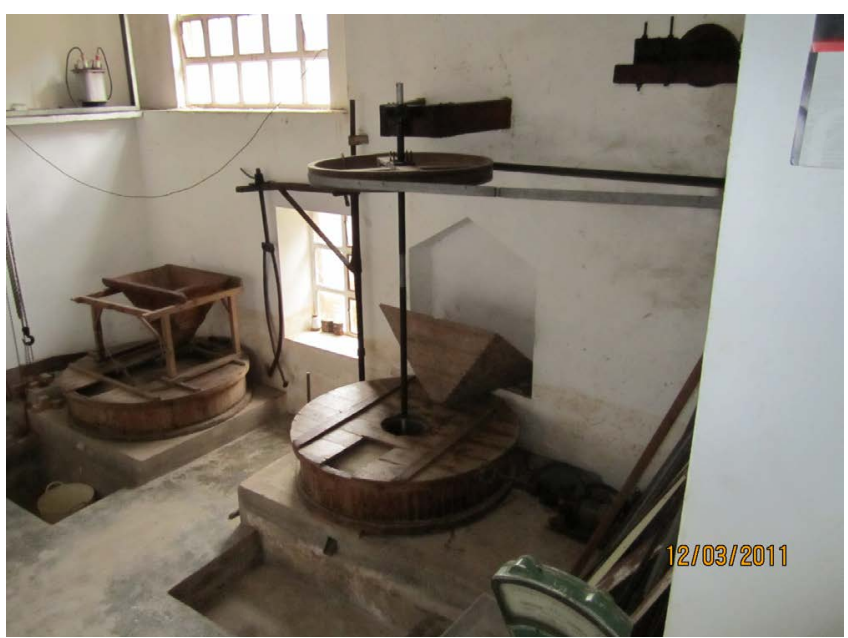

Figura 12. Sala de maquinaria: muelas

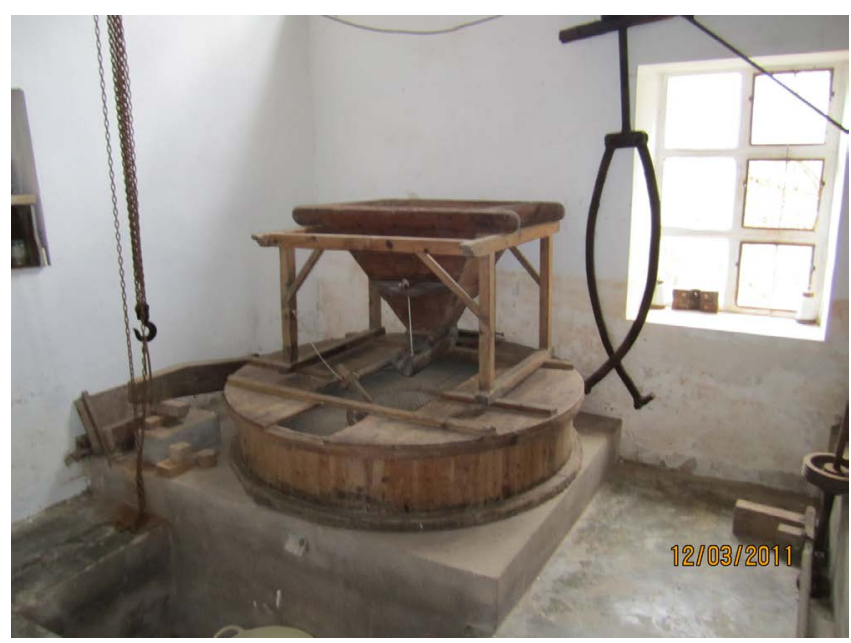

Figura 13. Sala de maquinaria: muela

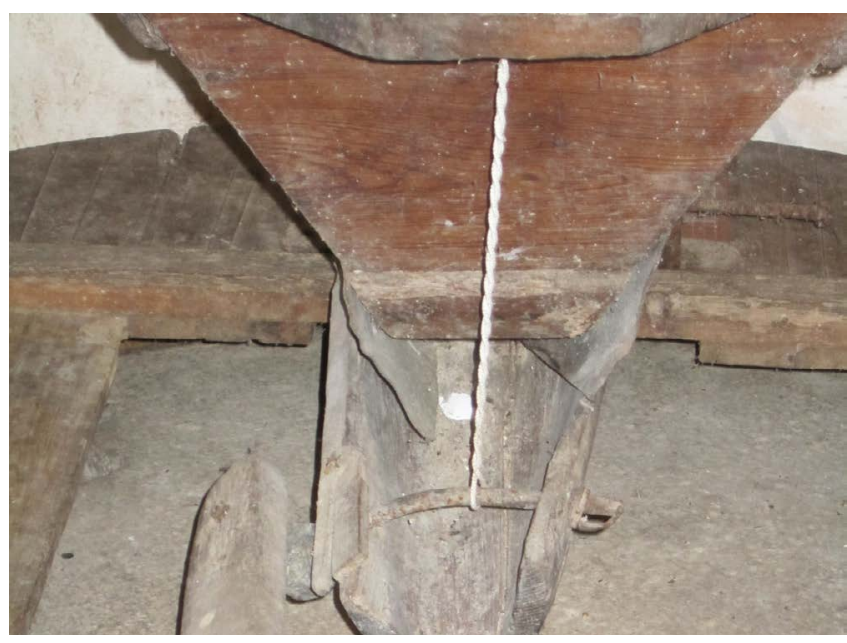

Figura 14. Detalle salida de la tolva

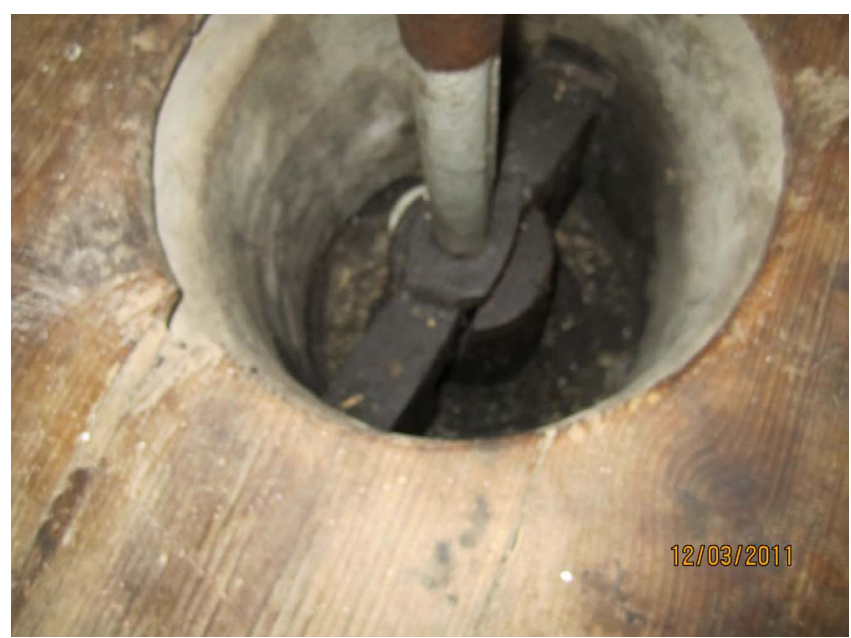

Figura 15. Detalle de las aspas 


\section{Referencias}

Benedito, Josep; López, F.; Melchor, J. M. y otros (1999). L’Arquitectura rural tradicional a Vila-real. Ajuntament de Vila-real.

Doñate Sebastiá, José M. a (1972). Datos para la Historia de Villarreal. Reproducción por facsímil. Valencia.

Gil Vicent, Vicent (director de la obra), Ferrer Navarro, Ramón y otros (2010). Història de Vila-real. Ajuntament de Vila-real.

Guinot Rodríguez, Enric y Selma Castell, Sergi (2002). Las acequias de la Plana de Castelló. Vol. 3 de Camins d’aigua. El Patrimonio hidráulico Valenciano. Generalitat Valenciana.

Heredia Robres, Jacinto (2009). Els noms de lloc al terme de Vila-real. Ateneu XXI.

Sociedad Castellonense de Cultura. Boletín de la Sociedad Castellonense de Cultura. Tomo LXVI. Enero-Marzo 1990Cuaderno I.

Traver, Benito (1909). Historia de Villarreal. Establecimiento Tipográfico de Juan Botella,

Fotografías: Salvador Tomás. 